\title{
Assessment of depression, anxiety and stress among Indian infertile couples in a tertiary health care centre in Bihar
}

\author{
Kalpana Singh $^{1}$, Kumari Shashi ${ }^{1 *}$, Kumari Rajshee ${ }^{2}$, Shivani Sinha ${ }^{3}$, Geetam Bharti ${ }^{1}$
}

\author{
${ }^{1}$ Department of Reproductive Medicine, Indira Gandhi Institute of Medical Sciences, Patna, Bihar, India \\ ${ }^{2}$ Department of Reproductive Medicine, Council of Scientific and Industrial Research - Central Food Technological \\ Research Institute, Mysore, Karnataka, India \\ ${ }^{3}$ Department of Community Medicine, Indira Gandhi Institute of Medical Sciences, Patna, Bihar, India
}

Received: 23 November 2019

Revised: 24 December 2019

Accepted: 31 December 2019

\section{* Correspondence:}

Dr. Kumari Shashi,

E-mail: shashi.nrs@gmail.com

Copyright: (c) the author(s), publisher and licensee Medip Academy. This is an open-access article distributed under the terms of the Creative Commons Attribution Non-Commercial License, which permits unrestricted non-commercial use, distribution, and reproduction in any medium, provided the original work is properly cited.

\begin{abstract}
Background: Infertility rate is on rising trend. It is often associated with a chronic state of stress which may manifest itself in anxiety-related and depressive symptoms. Also, the affected family faces social discrimination, ostracism and stigma which leads to increased anxiety or depression among infertile couples. The motive of this study was to assess the quality of life among infertile couples; to determine the relationship between various domains of quality of life of infertile couples i.e. emotional, mind/body, relational, social, environmental and tolerability and to determine the association of levels of quality of life of infertile couples with the selected variables visiting IGIMS.

Methods: This was a cross-sectional based study; carried out in the department of reproductive medicine, IGIMS, Patna, Bihar for one-year duration (January 2017 to December 2017), on 122 infertile patients attending outpatient department for treatment. Data was collected by using self-administered questionnaire i.e. Ferti QoL questionnaire and HADS.

Results: Among all these 96 cases was found to be suffering from primary infertility and 26 cases from secondary infertility. In primary infertile patient social domain was the most affected domain having the greatest impact on their quality of life. In secondary infertile patients the tolerability domain was the most affected domain having the greatest impact on their quality of life. The total fertility quality of life score in primary infertility patients showed a lesser quality of life (55.41) than secondary infertility patients (66.29).

Conclusions: This study points at the necessity of specific psychological interventions, presently absent from the public healthcare routine, for women struggling with infertility, to help them manage potential mental health problems and meet their reproductive goals.
\end{abstract}

Keywords: Anxiety, Depression, Fertility quality of life, Hospital anxiety and depression scale, Infertility, Questionnaire

\section{INTRODUCTION}

Infertility is commonly defined as the inability to conceive after 12 months of unprotected sexual intercourse. Infertility rate is on rising trend. On average 60-80 million couples in world suffer from infertility every year, among these 15-20 million (25\%) are in India alone. By study of WHO 2012, one in every four couples in developing countries is affected by infertility. This increased rate causes a homongous burden to the society. In some part of our country, infertility is linked to an act of god and punishment for sins of the past. The social 
pressure to bear children after marriage is so enormous, that women who are unable to produce child can be made to feel as something is dreadfully wrong with them, that they are somehow defective or being punished for something by the higher powers. These social taboos limit the awareness and incidence of infertility. The affected family faces social discrimination, ostracism and stigma which leads to either anxiety (a sense of tension, worry) or depression (a sense of loss and sadness). Anxiety and depression in infertile couple significantly affects their quality of life1-4 and all the domain of life, be it social domain (relation with society), emotional (response to any emotion), relational (relation with partners) and mind-body domain (cognition and behaviour). ${ }^{5}$

Despite the importance of psychiatric disorders in infertile couples, there has been little research on anxiety and depression assessment in infertile couples in recent years.

Cousineau TM et al found elevated depression levels in infertile women relative to fertile females. ${ }^{6}$ Greilet al, stated that infertile women are more likely to experience higher levels of distress than comparison groups. ${ }^{7}$ Population-based studies King RB and Klemetti R et al, found an increased likelihood of anxiety in sub fecund women in comparison of fecund controls. ${ }^{8,9}$ Psychosocial study of Verhaak et al, convincingly demonstrate a high incidence of negative reactions to infertility and its treatment. ${ }^{10}$ Recently it has been seen that fertility treatment in itself produces negative psychological effects. ${ }^{11}$ Infertility is found to be associated with some psychological strain, so it could be said that infertility may be considered as both cause as well as result of the psychological strain. ${ }^{4}$ According to meta-analysis of study conducted by Matthiesen et al, primary negative emotional response of infertility and assisted reproductive treatment (ART) is either in form of anxiety where women suffer from a sense of threat, tension or worry or in the form of depression where she suffer from a sense of loss, sadness, lack of control. ${ }^{12}$ A cross-sectional study conducted by Lakatos et al, concluded that ,compared to fertile women, infertile females are characterized by a significantly worse psychological status in terms of anxiety and depressive symptoms. ${ }^{13}$

Infertility is often associated with a chronic state of stress which may manifest itself in anxiety-related and depressive symptoms. The motive of this study is to highlight the associative relationship between stress and infertility among the visiting population in IGIMS, Patna, Bihar.

\section{Objectives of our study was}

- To assess depression, anxiety and stress among indian infertile couples in a tertiary health care centre

- To assess the quality of life among infertile couple
- To determine the relationship between various domains of quality of life of infertile couples i.e. emotional, mind/body, relational, social, environmental and tolerability.

- To determine the association of levels of quality of life of infertile couples with the selected variables.

\section{METHODS}

This was a cross-sectional based study; carried out in the department of reproductive medicine, IGIMS, Patna, Bihar for one-year duration on 122 infertile patients attending outpatient department for treatment with the

\section{Inclusion criteria}

- All infertile women and couples of age group: 18-45 year.

\section{Exclusion criteria}

- Patients not willing to participate in the study and patient suffering from chronic illness, HIV/hepatitis patients.

Purpose of the study was explained to the samples, the confidentiality of their responses was assured and their written consent was taken prior to the study. Data was collected by using self-administered questionnaire i.e. fertility quality of life (Ferti QoL) questionnaire and hospital anxiety and depression scale (HADS). Response of the samples were recorded accordingly for further data analysis. Demographic features like age, sex, education level, type of family (joint or nuclear), Social class was recorded per sample. Selected variables of sample were described using descriptive statistics i.e. frequency and percentage distribution. Assessment of quality of life was analysed by using descriptive statistics i.e. frequency and percentage distribution (\%). Karl Pearson correlation of coefficient method was used to find the correlation between various dimensions. Association of quality of life with selected variables was analysed by using descriptive statistics.

\section{Measurement tools}

Authors used standardized and validated as well as study specific questionnaires in order to assess certain psychological parameters related to reproductive health. Self-administered questionnaire i.e. fertility quality of life (Ferti Qol) questionnaire and hospital anxiety and depression scale (HADS) were used. 'Quality of life' (QoL) was defined by the World Health Organization (WHO) as an 'individuals' perception of their position in life in the context of the culture and value systems in which they live and in relation to their goals, expectations, standards and concerns (WHO QOL, 1995). Quality of life measurement is important to identify various aspects of fertility problems associated with poor QoLandto emphasize the need of advance research in 
health service-evaluation, patient satisfaction and policymaking through the use of a standard measurement tool Saxena et al. It comprises of various domains such as emotional well-being, social functioning, physical health, patient environment and personal beliefs (the WHOQOL Group; Skevington et al) and can be assessed with both generic and condition-specific instruments (Aaronson; Aignier et al; Luckett et al). Recently, an international collaboration of experts developed the fertility quality of life (Ferti QoL) questionnaire, which is condition-specific and aims to measure quality of life in all people experiencing fertility problems. The ferti QoL has demonstrated good psychometric properties. The ferti QoL tool was developed using mixed methods that comprised an (i) item generation phase with an expert panel (17 persons from 10 disciplines and 11 countries) and focus groups (136 patients from 6 countries) and (ii) a feasibility and acceptability phase (525 people with fertility problems from 10 countries) involving item analyses, factor analyses and reliability analysis. Ferti Qol was produced in English and translated into 20 languages including Hindi. It comprises two modules: the core-Ferti QoL module and the (optional) treatmentmodule. The treatment-module, which assesses current thoughts and feelings directly related to fertility treatment, was not used in the present study. The coreferti QoL module contains 24 items. Two items are general and 22 items specific to infertility covering four domains derived from the item-generation phase and exploratory factor analyses. The four domains are: mindbody (six items, e.g. 'Do your fertility problems interfere with your day-to-day work or obligations?'), relational (six items, e.g. 'Have fertility problems strengthened your commitment to your partner?'), social (six items, e.g. 'Are you socially isolated because of fertility problems?') and emotional (six items, e.g. 'Do you feel able to cope with your fertility problems?').

The second questionnaire comprised of HADS (hospital anxiety and depression scale). The HADS encompasses 14 items, equally subdivided into two scales measuring anxiety and depression (Zigmond and Snaith, Spinhoven et al). Hospital anxiety and depression scale has seven question related to assessment of anxiety and seven question for assessment of depression. Each item on the questionnaire is scored from $0-3$ and this means that a person can score between 0 and 21 for either anxiety or depression. A score of $0-7$ is normal, $8-10=$ borderline abnormal (borderline case) and 11-21 = abnormal (case).

\section{RESULTS}

Out of 122 cases, 34 cases belonged to age group 18-25 years, while the majority of cases i.e., 74 represented the age group of 26-35 years. Least number of cases i.e., 14 was observed in 36-45 age group. Among all these 96 cases was found to be suffering from primary infertility and 26 cases from secondary infertility (Table 1).

Table 1: Distribution of cases according to age and type of infertility.

\begin{tabular}{|llllll|}
\hline & & & Infertility & & Total \\
& \multirow{2}{*}{$18-25$} & Count & 34 & 0 & 34 \\
\cline { 2 - 6 } & & \% of total & $27.9 \%$ & $.0 \%$ & $27.9 \%$ \\
\cline { 2 - 6 } Age (in years) & \multirow{2}{*}{$26-35$} & Count & 54 & 20 & 74 \\
\cline { 2 - 6 } & & \% of total & $44.3 \%$ & $16.4 \%$ & $60.7 \%$ \\
\cline { 2 - 6 } & \multirow{2}{*}{$36-45$} & Count & 8 & 6 & 14 \\
\cline { 3 - 6 } & & \% of total & $6.6 \%$ & $4.9 \%$ & $11.5 \%$ \\
\hline \multirow{2}{*}{ Total } & & Count & $\mathbf{9 6}$ & $\mathbf{2 6}$ & $\mathbf{1 2 2}$ \\
\cline { 3 - 6 } & & \% of total & $\mathbf{7 8 . 7 \%}$ & $\mathbf{2 1 . 3 \%}$ & $\mathbf{1 0 0 . 0 \%}$ \\
\hline
\end{tabular}

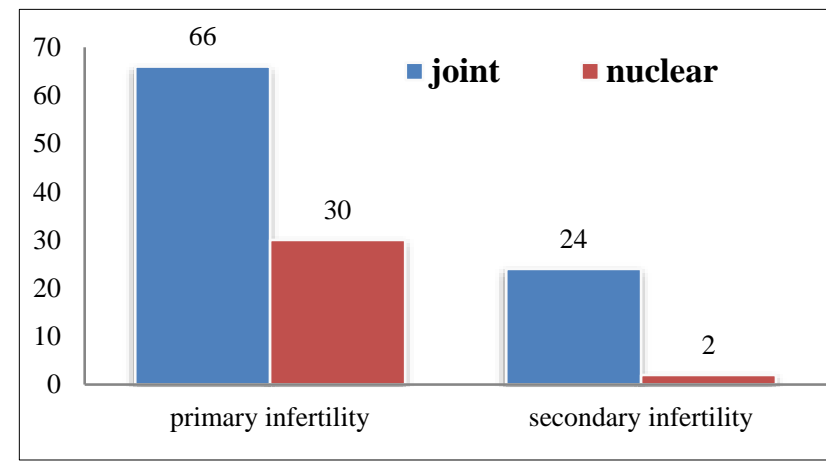

Figure 1: Distribution of cases according to type of family and type of infertility.

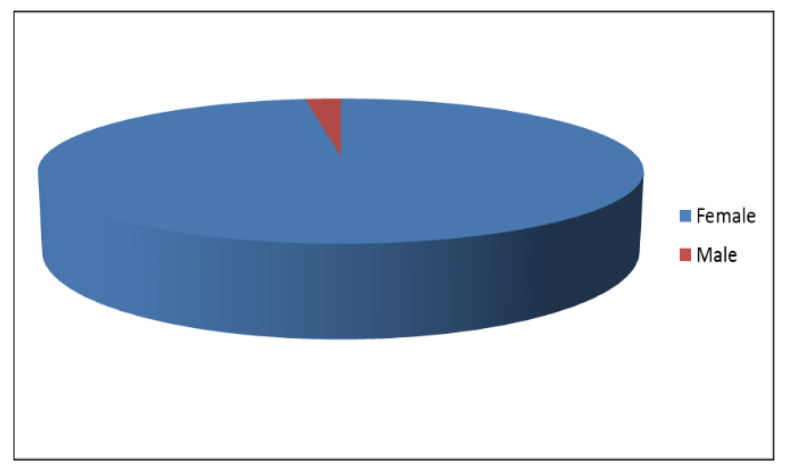

Figure 2: Distribution of cases according to sex. 
The family distribution among 122 cases was seen as 90 belonged to Joint family group among which 66 cases $(54.1 \%)$ showed primary infertility while 24 cases $(19.7 \%)$ showed secondary infertility. 32 of the cases represented Nuclear family among which 30 (24.6\%) showed primary infertility while only 2 case $(1.6 \%)$ showed secondary infertility (Figure 1).
Female represented the majority of cases that is 106 $(86.9 \%)$ while only 16 males who participated $(13.1 \%)$ were found to be infertile among the total cases. Out of 122 cases 96 cases $(78.7 \%)$ suffered from Primary infertility while 26 cases $(21.3 \%)$ suffered from secondary infertility (Figure 2).

Table 2: Distribution of cases according to social class and type of infertility.

\begin{tabular}{|c|c|c|c|c|c|c|}
\hline & & & \multicolumn{3}{|l|}{ Class } & \multirow{2}{*}{ Total } \\
\hline & & & Lower class & Middle class & Upper class & \\
\hline \multirow{4}{*}{ Infertility } & \multirow{2}{*}{ Primary } & Count & 16 & 78 & 2 & 96 \\
\hline & & $\%$ of total & $13.1 \%$ & $63.9 \%$ & $1.6 \%$ & $78.7 \%$ \\
\hline & \multirow[b]{2}{*}{ Secondary } & Count & 4 & 22 & 0 & 26 \\
\hline & & $\%$ of total & $3.3 \%$ & $18.0 \%$ & $0.0 \%$ & $21.3 \%$ \\
\hline \multirow{2}{*}{ Total } & & Count & 20 & 100 & 2 & 122 \\
\hline & & $\%$ of total & $16.4 \%$ & $82.0 \%$ & $1.6 \%$ & $100.0 \%$ \\
\hline
\end{tabular}

In social class 100 cases $(82 \%)$ were observed to be from middle class while 20 cases $(16.4 \%)$ were observed from lower class and only 2 case $(1.6 \%)$ was observed from upper class (Table 2).

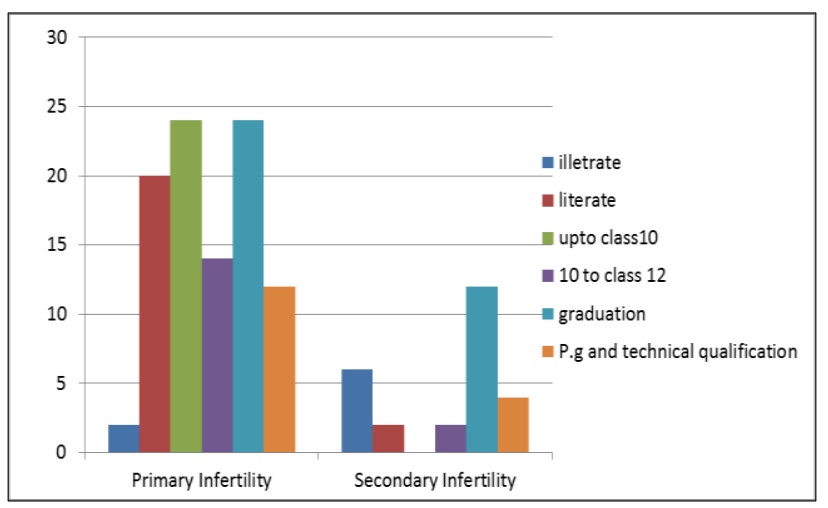

Figure 3: Distribution of cases according to their education.

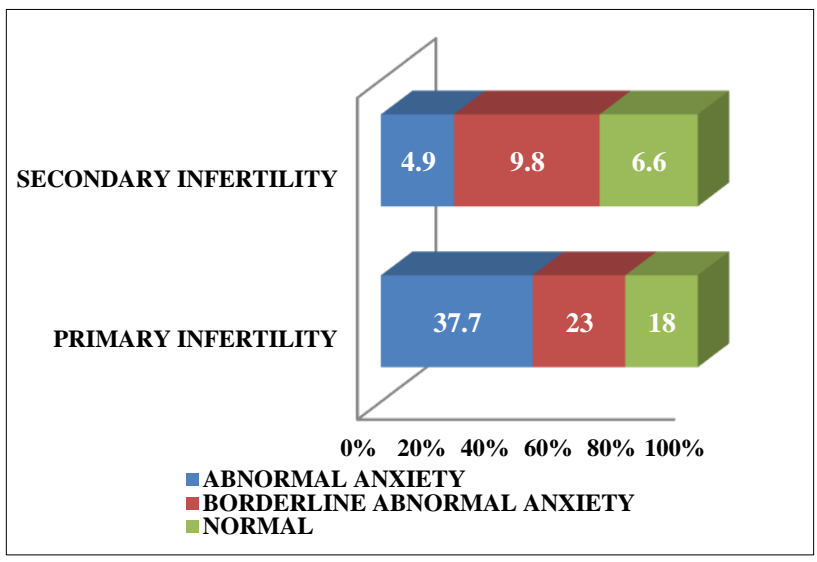

Figure 4: Distribution of patients according to anxiety among infertile patients by hads.
Level of education was varied among the infertility cases. $83 \%$ of the infertile patients represented the literate and educated background while $7 \%$ of the cases belonged to illiterate background (Figure 3).

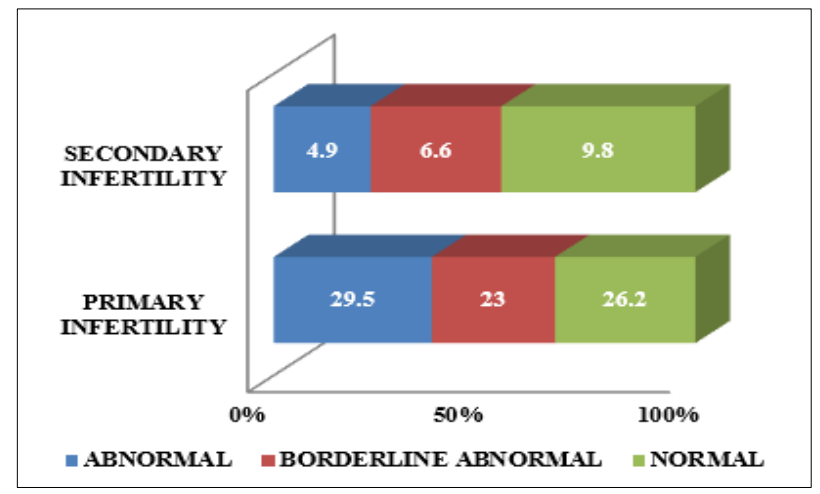

Figure 5: Distribution of patients according to depression among infertile patients by hads.

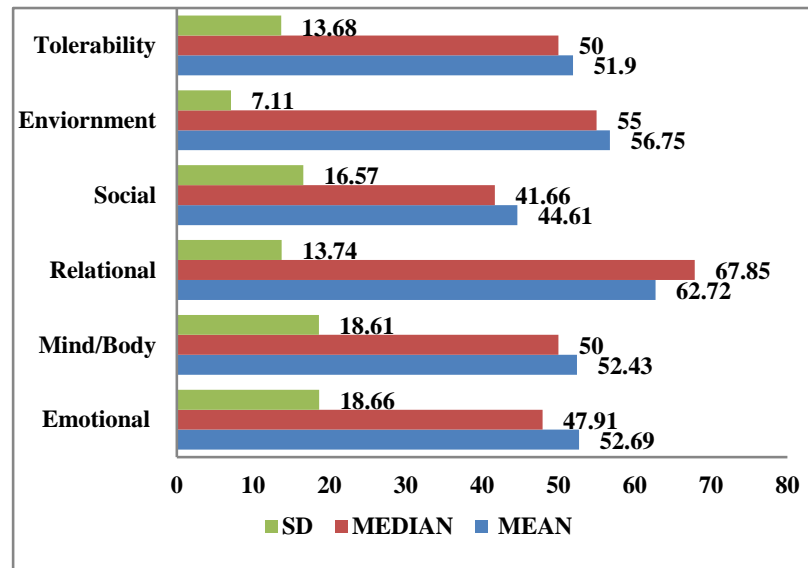

Figure 6: Distribution of patients according to quality of life scores of primary infertile patients. 
Anxiety levels of primary infertility patients were found to be as abnormal in 46 cases, borderline anxiety in 28 cases and Normal levels of Anxiety in 22 cases, whereas in secondary infertility patients only 6 cases were abnormal, 12 cases appeared as borderline abnormal and 8 cases appeared as normal (Figure 4 ).

Similarly, depression levels were found in 18 cases as abnormal, 14 cases as borderline abnormal and in 16 cases as normal. While in secondary infertile patients, 3 cases were found having abnormal depression, 4 cases having borderline depression levels and 6 cases having normal levels of depression (Figure 5).

Figure shows that the mean fertility quality of life scores of all the primary infertility cases. Infertility had influenced all the domains but social domain was the most affected in primary infertility patients. Domain wise ranking of quality of life (QOL) scores showed that the social domain had the lowest rank indicating that the social domain was the most affected domain having the greatest impact on their quality of life followed by mind/body, emotional, tolerability, environmental and relational domain. This indicates that Infertility is considered as a major taboo in society which sequentially impacts the quality of life (Figure 6).

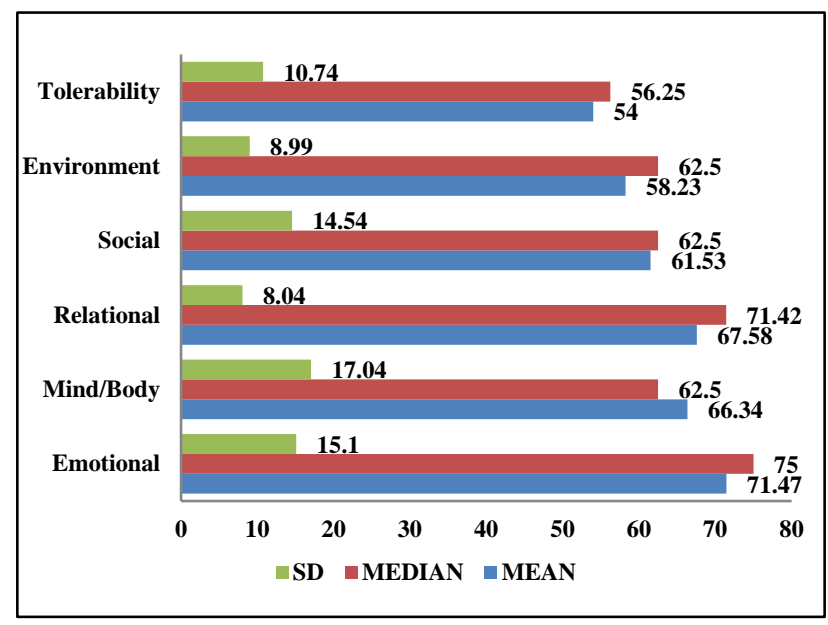

Figure 7: Distribution of patients according to quality of life scores of secondary infertile patients.

Figure shows that the mean fertility quality of life scores of all the domains of secondary infertility cases. Infertility had influenced all the domains but tolerability domain was the most affected in secondary infertility patients. Domain wise ranking of quality of life (QOL) scores showed that the tolerability domain had the lowest rank indicating that the tolerability domain was the most affected domain having the greatest impact on their quality of life followed by environmental, social, mind/body, relational and emotional domain. This indicates that desire of a second child could lead the cases to search for more medical facilities and options available in the area (Figure 7).
The total fertility quality of life score in primary infertility patients showed a lesser quality of life (55.41) than secondary infertility patients who had a better quality of life (66.29) (Figure 8).

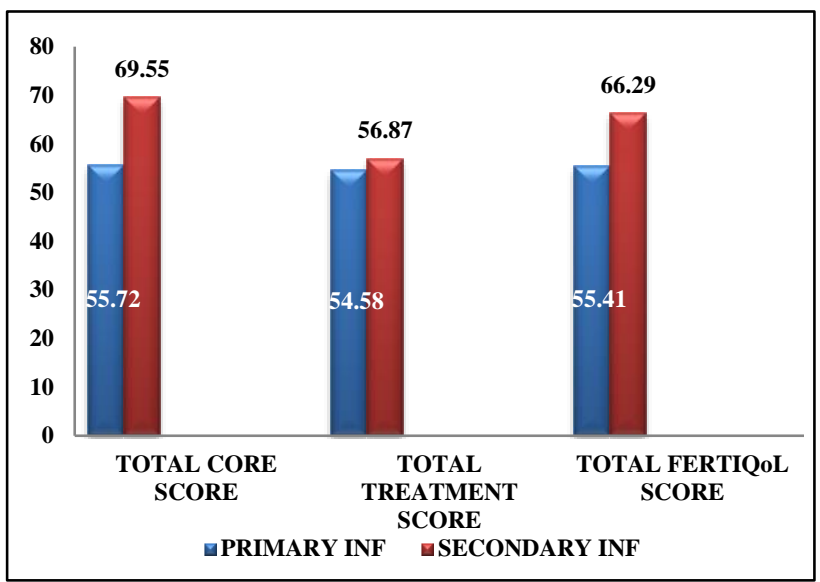

Figure 8: Total fertility quality of life scores of primary and secondary infertile patients.

\section{DISCUSSION}

The present study shows that the majority (44.3\%) of the infertile patients were in the age group of 26-35 years which was similar to the findings of a study conducted by Lakatoset al, which found that most of the infertile women were in the age group of 16-30 years. ${ }^{13}$ Majority of the patients $(78.7 \%)$ are having primary infertility while $21.3 \%$ are suffering from secondary infertility which is consistent with the findings from earlier research studies. Most of the infertile patients belonged to joint family $(73.8 \%)$ rather than nuclear family $(26.25 \%)$. This can be inferred as an increase of peer pressure on couples staying in joint family or there can be chance of less interaction among couples in the family.

Participation in the research study comprised of mainly female patients representing $86.9 \%$ of the cases while male participation was observed comparatively less $(13.1 \%)$. This indicates the belief in society which blames women primarily for infertility this can be associated with the Patriarchal system of the society which lets males to uphold their ego in such cases even.

Level of education was varied among the infertility cases. $83 \%$ of the infertile patients represented the literate and educated background while $7 \%$ of the cases belonged to illiterate background. Results of studied one about correlation of age and education with anxiety and/or depression were different than our study. Beutel $\mathrm{M}$ et al study concluded that age and education level have no significant relationship with depression and/or anxiety. ${ }^{14}$ But Domaret al, study showed that there was positive correlation between them. ${ }^{15}$

Anxiety level was comparatively seen more in primary infertile patients (37.7\%: abnormal anxiety) than in 
secondary infertile patients (4.9\%: abnormal anxiety). This implicates that primary infertility is seen as more stressed state in major of the cases of patients. Depression level was comparatively seen more in primary infertile patients $(29.5 \%)$ than in secondary infertile patients (4.9\%).it was seen that prevalence of anxiety was more than Arats et al study $(23.2 \%)$ but less than, Ramezanzadeh et al. ${ }^{16}$ (Females: $40.8 \%$ ), Alhassan et al, (Females: 62.0\%) and Domar et al, (Females: 36.7\%). ${ }^{17,18}$ Similar to anxiety level, depression of primary infertile patients was observed more than secondary. This can be associated with so many factors like social, emotional, relational situation of the cases. Primary infertility is seen as more worrying case in the studied patients. Most of the secondary infertility cases represented as the desire of a boy child or peer pressure of having more children.

In primary infertile patient social domain was the most affected domain having the greatest impact on their quality of life followed by mind/body, emotional, tolerability, environmental and relational domain .This indicates that Infertility is considered as a major taboo in society which sequentially impacts the quality of life (mind/body, emotional, tolerability, environmental and relational) of the infertile cases. In secondary infertile patients the tolerability domain was the most affected domain having the greatest impact on their quality of life followed by environmental, social, mind/body, relational and emotional domain. This indicates that desire of a second child could lead the cases to search for more medical facilities and options available in the area. The total Fertility quality of life score in primary infertility patients showed a lesser quality of life (55.41) than secondary infertility patients who had a better quality of life (66.29).

\section{CONCLUSION}

This study points at the necessity of specific psychological interventions, presently absent from the public healthcare routine. Secondary infertile cases had better quality of life than the primary infertile cases and there was a significant difference in the quality of life of these patients. Demographic characteristics showed a major impact on the infertility cases. Although society still sees female infertility as a taboo, awareness for male infertility can lessen the grievances suffered by females to a much extent.

Infertility affects all the domains but it has the major impact on the emotional aspect of the infertile couples hence it is needed that health professionals should include assessment of psychological symptomatology to plan more efficient interventions to infertile patients. Making Society aware of not defining infertility as a gender biased view can help in development of both male and female as an individual as such society norms can lead to imbalance of mind/body, relational and emotional domains of the patients.
Funding: No funding sources

Conflict of interest: None declared

Ethical approval: The study was approved by the Institutional Ethics Committee

\section{REFERENCES}

1. Verhaak CM, Smeenk J, Evers A, Kremer J, Kraaimaat F, Braat D. Women's emotional adjustment to IVF: a systematic review of 25 years of research. Hum Reprod Update. 2007;13:27-36.

2. Dancet E, Nelen W, Sermeus W, Leeuw De L, Kremer J, Hooghe TD. The Patients perspective on fertility care: a systematic review. Hum Reprod Update. 2010;16(5):467-87.

3. Chachamovich JR, Chachamovich E, Ezer H, Fleck MP, Knauth D, Passos EP. Investigating quality of life and health-related quality of life in infertility: a systematic review. J Psychosom Obstet Gynaecol. 2010;31(2):101-10.

4. Schmidt L. Psychosocial burden of infertility and assisted reproduction. J Lancet. 2006;367(9508):37980.

5. Boivin J, Takefman J, Braverman A. The fertility quality of life (FertiQoL) tool: development and general psychometric properties. Hum Reprod. 2011;26(8):2084-91.

6. Cousineau TM, Domar AD. Psychological impact of infertility. J Best Practice Res Clin Obstet Gynaecol. 2007;21(2):293-308.

7. Greil AL, Slauson-Blevins K, McQuillan J. The experience of infertility: a review of recent literature. Sociol Health Illn. 2010;32(1):140-62.

8. King RB. Subfecundity and anxiety in a nationally representative sample. Soc Sci Med. 2003;56(4):73951.

9. Klemetti R, Raitanen J, Sihvo S, Saarni S, Koponen P. Infertility, mental disorders and well-being-a nationwide survey. Acta Obstet Gynecol Scand. 2010;89(5):677-82.

10. Verhaak CM, Smeenk JM, Evers AW, Kremer JA, Kraaimaat FW, Braat DD. Women's emotional adjustment to IVF: a systematic review of 25 years of research. Hum Reprod Update. 2007;13(1):27-36.

11. Greil AL, McQuillan J, Lowry M, Shreffler KM. Infertility treatment and fertility-specific distress: a longitudinal analysis of a population-based sample of U.S. women. SocSci Med. 2011;73(1):87-94.

12. Matthiesen SM, Frederiksen $Y$, Ingerslev HJ, Zachariae R. Stress, distress and outcome of assisted reproductive technology (ART): a meta-analysis. Hum Reprod. 2011;26(10):2763-76.

13. Lakatos E, Szigeti JF, Ujma PP, Sexty R, Balog P. Anxiety and depression among infertile women: a cross-sectional survey from Hungary. BMC Women's Health. 2017;17:48.

14. Beutel M, Kupfer J, Kirchmeyer P, Kehde S, Kohn FM, Schroeder-Printzen I, et al. Treatment related stresses and depression in couples undergoing 
assisted reproductive treatment by IVF or ICSI. Androl. 1999;31:27-35.

15. Domar AD, Broome A, Zuttermeister PC, Seibel M, Friedman R. The prevalence and predictability of depression in infertile women. Fertil Steril. 1992;58(6):1158-63.

16. Aarts J, Empel IV, Boivin J, Nelen W, Kremer J, Verhaak C. Relationship between quality of life and distress in infertility: a validation study of the Dutch FertiQoL. Hum Reprod. 2011;26(5):1112-8.

17. Ramezanzadeh F, Aghssa MM, Abedinia N, Zayeri F, Khanafshar N, Shariat M, et al. A survey of relationship between anxiety, depression and duration of infertility. BMC Womens Health. 2004;4(1):9.

18. Alhassan A, Ziblim AR, Muntaka S. A survey on depression among infertile women in Ghana. BMC Womens Health. 2014;14(1):42.

Cite this article as: Singh K, Shashi K, Rajshee K, Sinha S, Bharti G. Assessment of depression, anxiety and stress among Indian infertile couples in a tertiary health care centre in Bihar. Int J Reprod Contracept Obstet Gynecol 2020;9:659-65. 